\title{
Nomenclature for Kidney Function and Disease: Executive Summary and Glossary from a Kidney Disease: Improving Global Outcomes (KDIGO) Consensus Conference
}

\author{
Andrew S. Levey ${ }^{a} \quad$ Kai-Uwe Eckardt ${ }^{b}$ Nijsje M. Dorman ${ }^{c}$ Stacy L. Christiansen ${ }^{d}$ \\ Michael Cheung ${ }^{\mathrm{e}}$ Michel Jadoul $^{\mathrm{f}}$ Wolfgang C. Winkelmayer ${ }^{\mathrm{g}}$ \\ ${ }^{a}$ Division of Nephrology, Tufts Medical Center, Boston, MA, USA; ${ }^{b}$ Department of Nephrology and Medical Intensive \\ Care, Charité-Universitätsmedizin Berlin, Berlin, Germany; ${ }^{C}$ Managing Editor, American Journal of Kidney Diseases, \\ Philadelphia, PA, USA; ${ }^{d}$ Managing Editor, Journal of the American Medical Association, Chicago, IL, USA; ${ }^{\mathrm{e} K i d n e y}$ \\ Disease: Improving Global Outcomes (KDIGO), Brussels, Belgium; ${ }^{f}$ Cliniques Universitaires Saint Luc, Université \\ Catholique de Louvain, Brussels, Belgium; ${ }^{9}$ Selzman Institute for Kidney Health, Section of Nephrology, Department \\ of Medicine, Baylor College of Medicine, Houston, TX, USA
}

A primary obligation of medical journals is the responsible, professional, and expeditious delivery of knowledge from researchers and practitioners to the wider community [1]. The task of journal editors, therefore, rests not merely in selecting what to publish, but in large measure judging how it can best be communicated. The challenge of improving descriptions of kidney function and disease in medical publishing was the impetus for a Kidney Disease: Improving Global Outcomes (KDIGO) Consensus Conference held in June 2019. The conference goals included standardizing and refining kidney-related nomenclature used in English-language scientific articles and developing a glossary that can be used by journals [2]

The rationale for the conference was that the worldwide burden of kidney disease is rising, but public aware-

This article is being published in Kidney International Reports and reprinted concurrently in several journals. The articles cover identical concepts and wording but vary in minor stylistic and spelling changes, detail, and length of manuscript, in keeping with each journal's style. Any of these versions may be used in citing this article. Excerpts are adapted with permission of KDIGO and the International Society of Nephrology.

\section{KARGER}

karger@karger.com www.karger.com/ajn (c) 2020 KDIGO Published by Karger Publishers on behalf of the International Society of Nephrology

This article is licensed under the Creative Commons AttributionNonCommercial-NoDerivatives 4.0 International License (CC BYNC-ND) (http://www.karger.com/Services/OpenAccessLicense) Usage and distribution for commercial purposes as well as any dis- ness remains limited, underscoring the need for effective communication by stakeholders in the kidney health community [3-6]. Despite this need, the nomenclature for describing kidney function and disease lacks uniformity and clarity. Two decades ago, a survey of hundreds of published articles and meeting abstracts reported a broad array of overlapping, confusing terms for chronic kidney disease (CKD) and advocated adoption of unambiguous terminology [7]. Nevertheless, terms flagged by that analysis as problematic, such as "chronic renal failure" and "pre-dialysis," still appear in current-day publications. A coherent, shared nomenclature could improve communication at all levels, to not only foster better appreciation of the burden of disease but also aid understanding of how patients feel about their disease, allow
Andrew S. Levey

Division of Nephrology, Tufts Medical Center

Box 391, 850 Washington Street

Boston, MA 02111 (USA)

alevey@tuftsmedicalcenter.org

Kai-Uwe Eckardt

Department of Nephrology and Medical Intensive Care

Charité-Universitätsmedizin Berlin

Augustenburger Platz 1, DE-13353 Berlin (Germany)

kai-uwe.eckardt@charite.de 
more effective communication between kidney disease specialists and other clinicians, advance more straightforward comparison and integration of datasets, enable better recognition of gaps in knowledge for future research, and facilitate more comprehensive public health policies for acute and chronic kidney disease.

Developing consistent, patient-centered, and precise descriptions of kidney function and disease in the scientific literature is an important objective to align communication in clinical practice, research, and public health. Although some terms have been in use for decades, the increased exchange of information among stakeholders makes it timely to revisit nomenclature in order to ensure consistency. The goal is to facilitate communication within and across disciplines and between practitioners and patients, with the ultimate hope of improving outcomes through consistency and precision.

Attendees at the conference included editors of kidney subspecialty journals, kidney subspecialty editors at general medical journals and journals from other subspecialties, experienced authors of clinical kidney health research, and patients. Guiding principles of the conference were that the revised nomenclature should be patient-centered, precise, and consistent with nomenclature used in the KDIGO guidelines (online suppl. Fig. S1; for all online suppl. material, see www.karger. com/doi/10.1159/000509359. Chronic kidney disease nomenclature used by KDIGO). The discussion focused on general description of acute and chronic kidney disease and kidney measures, rather than specific kidney diseases and particular measures of function and structure. Classifications of causes of kidney disease and procedures, performance measures, and outcome metrics for dialysis and transplantation were considered beyond the scope of discussion.

As described in detail in the conference report [8], the meeting attendees reached general consensus on the following recommendations: (i) to use "kidney" rather than "renal" or "nephro-" when referring to kidney disease and kidney function; (ii) to use "kidney failure" with appropriate descriptions of presence or absence of symptoms, signs, and treatment rather than "end-stage kidney disease"; (iii) to use the KDIGO definition and classification of acute kidney diseases and disorders (AKD) and acute kidney injury (AKI) rather than alternative descriptions to define and classify the severity of these; (iv) to use the KDIGO definition and classification of CKD rather than alternative descriptions to define and classify it; and (v) to use specific kidney measures, such as albuminuria or decreased glomerular filtration rate, rather than "abnor- mal" or "reduced" kidney function to describe alterations in kidney structure and function (Table 1). Accordingly, the proposed glossary contains 5 corresponding sections, and comprises specific items for which there was general agreement among the conference participants (https:// kdigo.org/conferences/nomenclature/; Table 2) [8]. For each section, the glossary includes preferred terms, abbreviations, descriptions, and terms to avoid, with the acknowledgment that journals may choose which of the recommendations to implement, and that journal style will dictate when and how to abbreviate terms to be consistent with nomenclature for other diseases.

A guiding principle for the development of the glossary was patient-centeredness. The Health and Medicine Division of the US National Academies of Sciences defines patient-centered care as "[p]roviding care that is respectful of, and responsive to, individual patient preferences, needs and values, and ensuring that patient values guide all clinical decisions" [9]. One of the 10 general principles recommended for redesign of the health system is: "Knowledge is shared and information flows freely. Patients should have unfettered access to their own medical information and to clinical knowledge. Clinicians and patients should communicate effectively and share information." In principle, the terms used to describe kidney function and disease should be understandable to all, with acknowledgment of variation in the level of health literacy. Use of multiple terms with similar meaning can lead to confusion, as can use of terms that forecast the future (such as "pre-dialysis") rather than describe the present. However, convergence of multiple names into an accepted set of terms does require that users of the glossary are willing to accept that labels that have been preeminent historically, and that may be more familiar or memorable even now, should now be superseded [10].

Of equal importance to patient-centeredness in the development of the glossary was precision, which can generally be defined as exactness or accuracy [10]. How medicine is defined and understood is changing rapidly from a descriptive, disease-based categorization in which multiple pathogenetic pathways may be conflated to a mechanism-based categorization that will promote more precise management of clinical problems. The latter approach, in which a molecular profile is added to the clinical and morphologic profile, has already revolutionized diagnosis and treatment in oncology. In nephrology, the ongoing Kidney Precision Medicine Project, funded by the National Institutes of Health, seeks to ethically obtain and evaluate kidney biopsies from participants with 
Table 1. Key takeaways from the conference

- Use the term "kidney" rather than "renal" to describe kidney function and kidney disease. In English, the terms renal and kidney are still used interchangeably, resulting in different acronyms describing the same condition or status (e.g., ESRD/ESKD and RRT/KRT). It is more likely that patients and the public would understand the terms incorporating the more familiar noun "kidney," rather than the less familiar adjective "renal," which is derived from Latin and is labeled as technical in some dictionaries. Although writing guides may generally favor using an appropriate adjective over a noun as a modifier, there are high-profile precedents for the use of kidney as a modifier, such as AKI, CKD, and NIDDK (National Institute of Diabetes and Digestive and Kidney Diseases).

- Avoid the term "end-stage." Although rooted in US law, the term is not patient sensitive, may connote a stigma, and may discourage advocacy. In the US, ESRD (ESKD) is a synonym for receipt of KRT. However, KRT is a treatment rather than a disease. The term "kidney failure," which is defined as GFR $<15 \mathrm{ml} / \mathrm{min}$ per $1.73 \mathrm{~m}^{2}$ or treatment by dialysis, is as comprehensive as "ESRD/ESKD," without suffering from its limitations.

- Improve characterization of the full spectrum of kidney failure. Although all patients with kidney failure have GFR $<15 \mathrm{ml} / \mathrm{min}_{\mathrm{per}} 1.73 \mathrm{~m}{ }^{2}$ or are undergoing treatment by dialysis, the severity of symptoms varies greatly. We lack terms to describe the severity of symptoms and signs, and yet they are indications for initiating KRT. There are also no common patient-reported outcome measures to describe severity. The term "kidney failure" in a chronic setting is defined as $>3$ months, whereas in an acute setting (i.e., AKI stage 3), it is reserved for a duration of $\leq 3$ months. Kidney failure could be further classified according to patient-reported outcomes (symptoms).

- Use more-descriptive terms for treatments for kidney failure. Many patients with kidney failure do not undergo KRT. The terms "treated" vs. "untreated" have been used, but this is not consistent with the idea that supportive care is indeed treatment. Furthermore, in some cases, patients choose supportive care rather than KRT; in other cases, they do not have a choice because of lack of insurance or lack of availability. Finally, some patients may not be under the care of a physician at all.

- Avoid the use of "chronic kidney disease (CKD)" as a synonym for "GFR $<60 \mathrm{ml} / \mathrm{min}$ per $1.73 \mathrm{~m}^{2}$." CKD includes markers of kidney damage or GFR $<60 \mathrm{ml} / \mathrm{min}$ per $1.73 \mathrm{~m}^{2}$ for $>3$ months, so ascertainment of GFR without assessment for markers of kidney damage is insufficient for classification of CKD status when GFR $>60 \mathrm{ml} / \mathrm{min}$ per $1.73 \mathrm{~m}^{2}$. If chronicity is not documented, it can be inferred on the basis of corroborative clinical data or presumed in the absence of clinical data to the contrary.

- Avoid the use of "acute kidney injury (AKI)" as a synonym for "acute kidney diseases and disorders (AKD)." AKD refers to kidney diseases and disorders with a duration of $\leq 3$ months, whereas AKI refers to kidney diseases and disorders with onset within 1 week.

- Use "CKD GFR and albuminuria categories" and "AKI stages" to describe disease severity, rather than employing ill-defined terms such as "mild," "moderate," "severe," and "advanced."

- Use the terms "GFR categories" and "albuminuria categories" rather than "CKD stages" when describing the level of GFR and albuminuria in populations either without CKD or without ascertainment of both GFR and albuminuria.

- Use the term "risk categories" to describe combinations of the G (GFR) and A (albuminuria) categories from the KDIGO heat map (see Supplementary Figure S1).

- Use specific terms, such as "GFR," "tubular secretion," "tubular reabsorption," "albuminuria," and "proteinuria," rather than general terms, such as "abnormal" or "reduced" kidney function, damage, or injury, when possible. Because kidney function comprises several functional categories, including excretory, endocrine, and metabolic functions, it should be described as specifically as possible. GFR is closely linked with the excretory function, but it should not be used as a synonym, because tubular reabsorption and excretion also contribute to excretory function.

- When referring to "decreased or decreasing GFR," avoid the use of different, poorly defined terms such as "impaired kidney function," "renal insufficiency," "renal dysfunction," "renal impairment," "worsening kidney function," and "kidney function decline."

- When referring to GFR, use descriptive abbreviations (mGFR for measured GFR and eGFR for estimated GFR, with specific notation based on the endogenous filtration markers used (e.g., $\mathrm{eGFR}_{\mathrm{cr}}, \mathrm{eGFR}_{\mathrm{cys}}$, and $\mathrm{GFR}_{\mathrm{cr}-\mathrm{cys}}$ ). Additional detail can be given in the methods. For mGFR, the methods should describe the exogenous filtration marker (e.g., inulin, iothalamate, iohexol) and clearance method (urinary clearance, plasma clearance). For eGFR, the methods should describe the estimating equation used (CKD-EPI; MDRD Study).

- Avoid referring to "albuminuria" or "proteinuria" as "decreased kidney function." Albuminuria and proteinuria are markers of kidney damage, rather than measures of kidney function.

- When referring to albuminuria or proteinuria, avoid the terms "microalbuminuria" and "macroalbuminuria/clinical proteinuria." Use the terms "moderately increased" or "severely increased" instead.

- When referring to albuminuria and proteinuria, use descriptive abbreviations, such as "urine albumin or protein excretion rates (AER and PER)" and "urine albumin-creatinine or protein-creatinine ratios (ACR and PCR)."

ACR, albumin-creatinine ratio; AER, albumin excretion rate; AKD, acute kidney diseases and disorders; AKI, acute kidney injury; CKD, chronic kidney disease; CKD-EPI, CKD Epidemiology Collaboration; eGFR, estimated glomerular filtration rate; $\mathrm{eGFR}_{\mathrm{cr}}$, estimated glomerular filtration rate derived from creatinine; $\mathrm{eGFR}_{\mathrm{cr}-\mathrm{cys}}$, estimated glomerular filtration rate derived from creatinine and cystatin $\mathrm{C} ; \mathrm{eGFR}_{\mathrm{cys}}$, estimated glomerular filtration rate derived from cystatin C; ESKD, end-stage kidney disease; ESRD, end-stage renal disease; GFR, glomerular filtration rate; KDIGO, Kidney Disease: Improving Global Outcomes; KRT, kidney replacement therapy; MDRD, Modification of Diet in Renal Disease; mGFR, measured glomerular filtration rate; NIDDK, National Institute of Diabetes and Digestive and Kidney Diseases; PCR, protein-creatinine ratio; PER, protein excretion rate; RRT, renal replacement therapy; US, United States. 
Table 2. KDIGO Kidney Function and Disease Glossary: suggested terms to describe kidney function and kidney disease, and criteria and measures defining them

\begin{tabular}{|c|c|c|c|}
\hline Preferred term & $\begin{array}{l}\text { Suggested } \\
\text { abbreviations }^{\mathrm{a}}\end{array}$ & Rationale/explanation & Terms to avoid \\
\hline
\end{tabular}

Part 1. Kidney Function and Disease

Kidney disease

Kidney function

Normal kidney function

Abnormal kidney function

Residual kidney function

RKF
The term "kidney" should be used preferentially when describing kidney disease and kidney function, with exceptions

"Renal," the prefix "nephro-" (except in the setting of specific functions, diseases, or syndromes; see below)

Reflects the entirety of acute kidney diseases and disorders and chronic kidney disease

Reflects the entirety of different and complex physiological functions of the kidney; should not be equated with glomerular filtration rate (GFR) only

General term applicable to various aspects of kidney function that should be specified

General term applicable to various aspects of kidney function that should be specified

Kidney function in people with kidney failure receiving KRT; further specification is required, e.g., urine flow rate, solute clearance. Although it is usually used in the setting of dialysis, this term could be used to refer to native kidney function in kidney transplant recipients.

Kidney structure

Normal kidney structure

Abnormal kidney structure

Causes of kidney disease
Reflects the entirety of different and complex structures of the kidney, ascertained by imaging and markers of injury and damage

General term applicable to various aspects of kidney structure that should be specified General term applicable to various aspects of kidney structure that should be specified

Cause of AKI, AKD, and CKD should be indicated whenever possible. Cause may be known, presumed, or unknown. Method for ascertainment and attribution of cause should be specified.

Part 2. Kidney Failure
Renal disease, nephropathy (except in the setting of specific diseases, e.g., membranous nephropathy)

Renal function (except when describing specific functions, e.g., renal acidification, renal concentrating mechanism)

Renal/kidney impairment, insufficiency, dysfunction; azotemia

Residual renal function (RRF)
Renal structure (except when describing specific structures within the kidney, such as artery, vein, capsule, parenchyma, cortex, medulla, glomeruli, tubules, interstitium, cysts, tumors)
GFR $<15 \mathrm{ml} / \mathrm{min}$ per $1.73 \mathrm{~m}^{2}$ or treatment by dialysis; further specification is required; see below
Cause should not be inferred only from presence of comorbid condition (such as diabetes)

Renal failure (RF); end-stage renal disease (ESRD); end-stage kidney disease (ESKD); renal disease; nephropathy; renal/kidney impairment, insufficiency, dysfunction; azotemia

Specification preferred

Duration

Acute kidney injury stage $3^{\mathrm{b}}$

AKI stage 3

Disease duration $\leq 3$ months

Acute renal failure; renal disease; nephropathy; renal/kidney impairment, insufficiency, dysfunction; azotemia; uremia Chronic renal failure; chronic renal disease; chronic nephropathy; chronic renal/kidney impairment, insufficiency, dysfunction; azotemia; uremia; irreversible kidney failure 
Table 2 (continued)

\begin{tabular}{|c|c|c|c|}
\hline Preferred term & $\begin{array}{l}\text { Suggested } \\
\text { abbreviations }\end{array}$ & Rationale/explanation & Terms to avoid \\
\hline \multicolumn{2}{|l|}{ Symptoms and signs } & \multicolumn{2}{|l|}{$\begin{array}{l}\text { Specification preferred (with, without, or unknown } \\
\text { symptoms and signs); with symptoms and signs would } \\
\text { be synonymous with uremia } \\
\text { A syndrome consisting of symptoms and signs } \\
\text { associated with kidney failure (does not indicate a causal } \\
\text { role for urea) }\end{array}$} \\
\hline \multicolumn{2}{|l|}{ Treatment } & \multicolumn{2}{|l|}{ Specification required } \\
\hline Kidney replacement therapy ${ }^{c}$ & KRT & $\begin{array}{l}\text { Further specification is required; includes dialysis and } \\
\text { transplantation }\end{array}$ & Renal replacement therapy (RRT) \\
\hline Dialysis & $\begin{array}{l}\text { AKI stage 3D } \\
\text { CKD G5D }\end{array}$ & $\begin{array}{l}\text { AKI stage } 3 \text { treated by dialysis } \\
\text { CKD G5 treated by dialysis }\end{array}$ & $\begin{array}{l}\text { AKI-D, dialysis-dependent AKI } \\
\text { ESKD, ESKF, ESRD, ESRF, } \\
\text { dialysis-dependent CKD }\end{array}$ \\
\hline Duration & & $\begin{array}{l}\text { Long-term vs. short-term: long-term refers to dialysis for } \\
\text { CKD, and may also be referred to as maintenance } \\
\text { dialysis; short-term refers to dialysis for AKD }\end{array}$ & $\begin{array}{l}\text { Chronic dialysis, acute dialysis (the } \\
\text { terms acute and chronic refer to } \\
\text { duration of kidney disease rather } \\
\text { than duration of dialysis } \\
\text { treatment) }\end{array}$ \\
\hline \multicolumn{2}{|l|}{ Modality and frequency } & \multicolumn{2}{|l|}{$\begin{array}{l}\text { Modalities } \\
\text { • hemodialysis (HD) } \\
\text { - hemofiltration (HF) } \\
\text { - hemodiafiltration (HDF) } \\
\text { - peritoneal dialysis (PD, ambulatory or automated) } \\
\text { Frequency } \\
\text { - continuous } \\
\text { - intermittent (short or prolonged) }\end{array}$} \\
\hline $\begin{array}{l}\text { Kidney transplantation } \\
\text { Donor source }\end{array}$ & CKD G1T-G5T & $\begin{array}{l}\text { CKD G1-G5 after transplantation } \\
\text { Specify living donor kidney transplant/transplantation } \\
\text { (LDKT) or deceased donor kidney transplant/ } \\
\text { transplantation (DDKT) }\end{array}$ & ESKD, ESKF, ESRD, ESRF \\
\hline $\begin{array}{l}\text { Kidney failure with replacement } \\
\text { therapy }\end{array}$ & KFRT & $\begin{array}{l}\text { CKD G5 treated by dialysis or CKD G1-G5 after } \\
\text { transplantation; for epidemiologic studies, both should } \\
\text { be included }\end{array}$ & ESKD, ESKF, ESRD, ESRF \\
\hline \multirow{2}{*}{$\begin{array}{l}\text { Kidney failure without replacement } \\
\text { therapy } \\
\text { With comprehensive } \\
\text { conservative care } \\
\text { Without comprehensive } \\
\text { conservative care }\end{array}$} & \multirow[t]{2}{*}{$\begin{array}{l}\text { CKD G5 } \\
\text { without KRT }\end{array}$} & $\begin{array}{l}\text { Further specification is preferred: specify whether KRT } \\
\text { is not chosen vs. not available } \\
\text { Further specification is preferred; definition is evolving }\end{array}$ & \multirow[t]{2}{*}{$\begin{array}{l}\text { ESKD, ESKF, ESRD, ESRF, } \\
\text { untreated kidney failure }\end{array}$} \\
\hline & & $\begin{array}{l}\text { Further specification is preferred: specify whether } \\
\text { comprehensive conservative care is not chosen vs. not } \\
\text { available }\end{array}$ & \\
\hline \multicolumn{2}{|l|}{$\begin{array}{l}\text { Part 3. Acute Kidney Diseases and } \\
\text { Disorders (AKD) and Acute Kidney } \\
\text { Injury (AKI) }\end{array}$} & $\begin{array}{l}\text { Disease duration } \leq 3 \text { months; conceptually different from } \\
\text { initial recognition of CKD }\end{array}$ & $\begin{array}{l}\text { Acute renal failure (ARF); acute } \\
\text { renal insufficiency (ARI) }\end{array}$ \\
\hline Acute kidney diseases & $\mathrm{AKD}^{\mathrm{c}}$ & $\begin{array}{l}\text { KDIGO definition: AKI, or GFR }<60 \mathrm{ml} / \mathrm{min} \text { per } 1.73 \\
\mathrm{~m}^{2} \text {, or markers of kidney damage for } \leq 3 \text { months, or } \\
\text { decrease in GFR by } \geq 35 \% \text { or increase in SCr by }>50 \% \text { for } \\
\leq 3 \text { months }\end{array}$ & ARF, ARI \\
\hline Acute kidney injury & AKI & $\begin{array}{l}\text { KDIGO definition (AKI is a subcategory of AKD): } \\
\text { oliguria for }>6 \text { hours, rise in SCr by }>0.3 \mathrm{mg} / \mathrm{dL} \text { in } 2 \text { days } \\
\text { or by }>50 \% \text { in } 1 \text { week }\end{array}$ & ARF, ARI \\
\hline \multicolumn{2}{|l|}{ AKI classification } & $\begin{array}{l}\text { KDIGO classification by cause and stage preferred rather } \\
\text { than stage alone; e.g., a patient with AKI stage } 3 \text { due to } \\
\text { ATN; classification applies to all AKI stages }\end{array}$ & $\begin{array}{l}\text { Previous classifications, including } \\
\text { RIFLE and AKIN (the KDIGO } \\
\text { classification harmonized these } \\
\text { prior definitions) }\end{array}$ \\
\hline \multirow[t]{4}{*}{ AKI stages } & & KDIGO definition (applicable only to people with AKI) & \\
\hline & AKI stage 1 & Serum creatinine and/or urine output criteria & \\
\hline & AKI stage 2 & Serum creatinine and/or urine output criteria & \\
\hline & AKI stage 3 & Serum creatinine and/or urine output criteria & \\
\hline
\end{tabular}


Table 2 (continued)

\begin{tabular}{lll}
\hline Preferred term & $\begin{array}{l}\text { Suggested } \\
\text { abbreviations }\end{array}$ & Rationale/explanation \\
\hline Part 4. Chronic Kidney Disease (CKD) & Disease duration $>3$ months \\
\hline CKD & \\
\hline CKD classification & $\begin{array}{l}\text { KDIGO definition: GFR }<60 \mathrm{ml} / \mathrm{min} \text { per } 1.73 \mathrm{~m}^{2} \text { or } \\
\text { markers of kidney damage for }>3 \text { months }\end{array}$ \\
& $\begin{array}{l}\text { KDIGO CGA classification by cause, GFR category } \\
\text { (G1-G5), and albuminuria category (A1-A3); see below } \\
\text { for definitions of G and A categories. For example, a } \\
\text { patient with CKD G1, A3 due to diabetes, or a cohort } \\
\text { with CKD G4-G5, A1-A3 of any cause. Note that CKD } \\
\text { classification is only applicable to people with CKD, so a } \\
\text { patient could not be classified as "CKD G2, A1" if there } \\
\text { was no other evidence of kidney damage. } \\
\text { CKD G1-G5, A1-A3 of any cause, not receiving dialysis } \\
\text { or transplantation }\end{array}$ \\
& $\begin{array}{l}\text { CKD without } \\
\text { KRT }\end{array}$
\end{tabular}

Terms to avoid

Chronic renal failure (CRF); ESRD; renal/kidney impairment, insufficiency, dysfunction

CRF; ESRD; renal/kidney impairment, insufficiency, dysfunction

Mild, moderate, severe, early, advanced CKD; CKD stage 1-5 (complete description preferred rather than $\mathrm{G}$ category alone)

ND-CKD (non-dialysis CKD), NDD-CKD (non-dialysisdependent $\mathrm{CKD}$ ), predialysis CKD, pre-ESRD CKD

\section{CKD risk categories}

CKD risk category - low

Low risk

KDIGO definitions (colors refer to heat map in Supplementary Figure S1) unless otherwise defined; risk depends on the outcome being considered

CKD risk category moderately high

CKD risk category - high

CKD risk category - very high

Moderate risk

High risk

Very high risk
Refers to G1A1, G2A1 (green)

Refers to G1A2, G2A2, G3aA1 (yellow)

Refers to G1A3, G2A3, G3aA2, G3bA1 (orange)

Refers to G3aA3, G3bA2, G3bA3, G4A1, G4A2, G4A3, G5A1, G5A2, G5A3 (red)
Mild, moderate, severe, early, advanced CKD

Refers to worsening GFR or albuminuria. Other biomarkers not included. There is not yet consensus on use of specific terms to describe the timing (e.g., early, late) or rate (fast, slow) of progression. Use of specific terms should be defined in methods.

Further specification may be required: GFR decline may occur during therapy for other conditions, which may not be considered as CKD progression.

CKD remission

Refers to improving GFR or albuminuria. Criteria depend on disease. Use of specific terms should be defined in methods.

Part 5. Kidney Measures

Applies to people with or without kidney disease; consider measurement issues (methods) and variability (multiple measures may improve classification)

\begin{tabular}{|c|c|c|}
\hline \multicolumn{2}{|c|}{ Glomerular filtration rate and clearance } & GFR and creatinine clearance are not synonymous \\
\hline Glomerular filtration rate & GFR & Units must be specified (ml/min per $1.73 \mathrm{~m}^{2}$ or $\mathrm{ml} / \mathrm{min}$ ) \\
\hline $\begin{array}{l}\text { Measured glomerular } \\
\text { filtration rate }\end{array}$ & mGFR & $\begin{array}{l}\text { Clearance methods and exogenous filtration markers } \\
\text { should be noted separately in methods }\end{array}$ \\
\hline $\begin{array}{l}\text { Estimated glomerular } \\
\text { filtration rate }\end{array}$ & eGFR & $\begin{array}{l}\text { Estimating equations (e.g., CKD-EPI and MDRD Study) } \\
\text { and filtration markers (e.g., creatinine and cystatin C) } \\
\text { should be noted separately in methods }\end{array}$ \\
\hline \multirow{3}{*}{$\begin{array}{l}\text { Estimated glomerular } \\
\text { filtration rate; marker }\end{array}$} & $\mathrm{eGFR}_{\mathrm{cr}}$ & eGFR using creatinine \\
\hline & $e G_{\text {cys }}$ & eGFR using cystatin C \\
\hline & $\mathrm{eGFR}_{\text {cr-cys }}$ & eGFR using creatinine and cystatin C \\
\hline Clearance & $\mathrm{Cl}$ & $\begin{array}{l}\text { Solute must be specified; units must be specified }(\mathrm{ml} / \mathrm{min} \\
\left.\text { per } 1.73 \mathrm{~m}^{2} \text { or } \mathrm{ml} / \mathrm{min}\right)\end{array}$ \\
\hline Measured clearance & $\mathrm{mCl}$ & $\begin{array}{l}\text { Clearance methods and markers should be noted } \\
\text { separately in methods }\end{array}$ \\
\hline
\end{tabular}


Table 2 (continued)

\begin{tabular}{clll}
\hline Preferred term & $\begin{array}{l}\text { Suggested } \\
\text { abbreviations }\end{array}$ & Rationale/explanation & Terms to avoid \\
\hline Measured clearance; marker & $\mathrm{mCl}_{\mathrm{UN}}$ & $\mathrm{mCl}$ using urea nitrogen \\
& $\mathrm{mCl}_{\mathrm{cr}}$ & $\mathrm{mCl}$ using creatinine \\
Estimated clearance & $\mathrm{mCl}_{\mathrm{UN}-\mathrm{cr}}$ & $\mathrm{mCl}$ using urea nitrogen and creatinine \\
Estimated clearance; marker & $\mathrm{eCl}$ & $\begin{array}{l}\text { Estimating equations (e.g., Cockcroft-Gault) and } \\
\text { markers should be noted separately in methods }\end{array}$ & eCl using creatinine \\
\hline
\end{tabular}

GFR categories

$\begin{array}{ll}\begin{array}{ll}\text { Normal to increased GFR } \\ \text { Mildly reduced GFR }\end{array} & \text { G1 } \\ \text { Moderately reduced GFR } & \text { G3a } \\ & \text { G3b } \\ \text { Severely reduced GFR } & \text { G4 } \\ \text { Kidney failure } & \text { G5 } \\ \text { Hyperfiltration } & \end{array}$

GFR reserve
For use in describing GFR level irrespective of the presence or absence of kidney disease; GFR units are $\mathrm{ml} /$ min per $1.73 \mathrm{~m}^{2}$ for these categories; multiple categories can be collapsed (e.g., G3-G5) GFR $\geq 90 \mathrm{ml} / \mathrm{min}$ per $1.73 \mathrm{~m}^{2}$ GFR $60-89 \mathrm{ml} / \mathrm{min}$ per $1.73 \mathrm{~m}^{2}$ GFR $45-59 \mathrm{ml} / \mathrm{min}$ per $1.73 \mathrm{~m}^{2}$ GFR $30-44 \mathrm{ml} / \mathrm{min}$ per $1.73 \mathrm{~m}^{2}$ GFR $15-29 \mathrm{ml} / \mathrm{min}$ per $1.73 \mathrm{~m}^{2}$ GFR $<15 \mathrm{ml} / \mathrm{min}$ per $1.73 \mathrm{~m}^{2}$ or treated by dialysis The concept of hyperfiltration is generally accepted but Renal hyperfiltration not consistently defined. If this term is used as an exposure, outcome, or covariate, the GFR threshold must be defined (e.g., $>120 \mathrm{ml} / \mathrm{min}$ per $1.73 \mathrm{~m}^{2}$ ). The concept of GFR reserve is generally accepted as the Renal function reserve difference between stimulated and basal GFR

\section{Albuminuria and proteinuria}

Specify measurement conditions (spot vs. timed samples; quantitative vs. dipstick); differentiate non-albumin proteins as clinically indicated

\begin{tabular}{ll}
\hline Albuminuria \\
$\begin{array}{l}\text { Urinary albumin concentration } \\
\text { Urinary albumin excretion rate }\end{array} \quad$ AER & $\begin{array}{l}\text { Requires timed urine collection; interval for urine } \\
\text { collection should be noted separately in methods; unit of } \\
\text { time may vary (hour or day) }\end{array}$ \\
Urinary albumin-creatinine ratio & ACR $\quad \begin{array}{l}\text { From timed urine collection or spot urine collection; } \\
\text { interval for timed urine collection, or time of day for } \\
\text { spot urine collection, should be noted separately in } \\
\text { methods }\end{array}$
\end{tabular}

\section{Proteinuria}

Urinary protein concentration

Urinary protein excretion rate

Urinary protein-creatinine ratio
PER

PCR
Microalbuminuria, macroalbuminuria
Clinical proteinuria, overt proteinuria

Requires timed urine collection; interval for urine collection should be noted separately in methods; unit of time may vary (hour or day)

From timed urine collection or spot urine collection; interval for timed urine collection, or time of day for spot urine collection, should be noted separately in methods

\section{Albuminuria and proteinuria categories \\ Normal \\ Mildly increased (mild) \\ Normal to mildly increased (normal A1 \\ to mild) \\ Moderately increased (moderate) A2}

Severely increased (severe)
For use in describing albuminuria or proteinuria level irrespective of the presence or absence of kidney disease AER $<10 \mathrm{mg} / \mathrm{d} ;$ ACR $<10 \mathrm{mg} / \mathrm{g}(<1 \mathrm{mg} / \mathrm{mmol})$ AER $10-29 \mathrm{mg} / \mathrm{d}$; ACR $10-29 \mathrm{mg} / \mathrm{g}(1.0-2.9 \mathrm{mg} / \mathrm{mmol})$

AER $<30 \mathrm{mg} / \mathrm{d}$; ACR $<30 \mathrm{mg} / \mathrm{g}(<3 \mathrm{mg} / \mathrm{mmol})$

PER $<150 \mathrm{mg} / \mathrm{d}$; PCR $<150 \mathrm{mg} / \mathrm{g}(<15 \mathrm{mg} / \mathrm{mmol})$

AER $30-300 \mathrm{mg} / \mathrm{d}$; ACR $30-300 \mathrm{mg} / \mathrm{g}(3-30 \mathrm{mg} / \mathrm{mmol})$

PER 150-500 mg/d; PCR 150-500 mg/g (15-50 mg/ $\mathrm{mmol})$

AER $>300 \mathrm{mg} / \mathrm{d} ;$ ACR $>300 \mathrm{mg} / \mathrm{g}(>30 \mathrm{mg} / \mathrm{mmol})$ PER $>500 \mathrm{mg} / \mathrm{d}$; PCR $>500 \mathrm{mg} / \mathrm{g}(>50 \mathrm{mg} / \mathrm{mmol})$
Normoalbuminuria

Microalbuminuria

Macroalbuminuria, clinical proteinuria, overt proteinuria
Nomenclature for Kidney Function and Disease 
Table 2 (continued)

\begin{tabular}{|c|c|c|c|}
\hline Preferred term & $\begin{array}{l}\text { Suggested } \\
\text { abbreviations }^{\mathrm{a}}\end{array}$ & Rationale/explanation & Terms to avoid \\
\hline Nephrotic-range/syndrome ${ }^{\mathrm{d}}$ & & $\begin{array}{l}\text { AER }>2200 \mathrm{mg} / \mathrm{d} ; \text { ACR }>2200 \mathrm{mg} / \mathrm{g}(>220 \mathrm{mg} / \mathrm{mmol}) \\
\mathrm{PER}>3500 \mathrm{mg} / \mathrm{d} \text {; PCR }>3500 \mathrm{mg} / \mathrm{g}(>350 \mathrm{mg} / \mathrm{mmol}) \\
\text { Specify with or without nephrotic syndrome, as noted by } \\
\text { the presence of hypoalbuminemia (with edema and } \\
\text { hyperlipidemia in most cases) }\end{array}$ & \\
\hline Tubular secretion & TS & $\begin{array}{l}\text { Further specification is required to distinguish rate, } \\
\text { clearance, or fraction (compared to filtered load) }\end{array}$ & \\
\hline Tubular reabsorption & TR & $\begin{array}{l}\text { Further specification is required to distinguish rate, } \\
\text { clearance, or fraction (compared to filtered load) }\end{array}$ & \\
\hline Fractional excretion, marker & $\mathrm{FE}_{\mathrm{Na}}$ & FE of sodium & \\
\hline Fractional reabsorption, marker & $\mathrm{FR}_{\mathrm{Na}}$ & FR of sodium & \\
\hline
\end{tabular}

ACR, albumin-creatinine ratio; AER, albumin excretion rate; AKD, acute kidney diseases and disorders; AKI, acute kidney injury; AKIN, Acute Kidney Injury Network; ARF, acute renal failure; ARI, acute renal insufficiency; ATN, acute tubular necrosis; CGA, cause, GFR category, and albuminuria category; CKD, chronic kidney disease; CKD-EPI, CKD Epidemiology Collaboration; DDKT, deceased donor kidney transplant/transplantation; eGFR, estimated glomerular filtration rate; ESKD, end-stage kidney disease; ESKF, end-stage kidney failure; ESRD, end-stage renal disease; ESRF, end-stage renal failure; $\mathrm{FE}_{\mathrm{Na}}$, fractional excretion, sodium; $\mathrm{FR}_{\mathrm{Na}}$, fractional reabsorption, sodium; GFR, glomerular filtration rate; HD, hemodialysis; $\mathrm{HDF}$, hemodiafiltration; HF, hemofiltration; KDIGO, Kidney Disease: Improving Global Outcomes; KFRT, kidney failure with replacement therapy; KRT, kidney replacement therapy; LDKT, living donor kidney transplant/transplantation; MDRD, Modification of Diet in Renal Disease; mGFR, measured GFR; ND-CKD, non-dialysis CKD; NDD-CKD, non-dialysis-dependent CKD; PCR, protein-creatinine ratio; PD, peritoneal dialysis; PER, protein excretion rate; pre-ESRD, pre-end-stage renal disease; RF, renal failure; RIFLE, Risk, Injury, Failure, Loss of kidney function, and End-stage kidney disease; RRT, renal replacement therapy; SCr, serum creatinine; TR, tubular reabsorption; TS, tubular secretion. ${ }^{\mathrm{a}}$ Journal style will dictate whether and when to abbreviate terms. ${ }^{\mathrm{b}}$ Ongoing discussion; may be revised by KDIGO AKI guideline update. ${ }^{\mathrm{c}}$ Ongoing discussion; may be revised by KDIGO AKD consensus conference. ${ }^{\mathrm{d}}$ Ongoing discussion; may be revised by KDIGO Glomerulonephritis guideline update.

AKI or CKD; create a kidney tissue atlas; define disease subgroups; and identify cells, pathways, and targets for novel therapies [11]. As has occurred in oncology, it is anticipated that refinements that result in more precise disease descriptions will be incorporated into current nomenclature for kidney function and disease, rather than replace it altogether. Thus, although the glossary is designed to be consistent with current knowledge and stable enough to remain relevant for the foreseeable future, it is also intended to be sufficiently flexible to accommodate new vocabulary arising with advances in the field.

A central strength of the proposed glossary is that it is based on existing KDIGO definitions, classifications, and nomenclature for acute and chronic kidney disease. In addition, it was developed using the following: a systematic process, including articulation of a clear and transparent rationale (patient-centeredness and precision); capture of stakeholder viewpoints via patient focus groups [12] and a corresponding survey; a period of public comment on conference scope; and attainment of consensus among attendees at the conference. Although the recommendations are not likely to answer all concerns, the consensus among conference attendees was that standardizing scientific nomenclature is a necessary first step to im- proving communications among clinicians, researchers, and public health officials, and with patients, their families and caregivers, and the public.

Limitations of the proposed glossary are that it is restricted to English (nuances may be difficult to translate); only a limited number of stakeholders were able to participate, owing to practical reasons; it is not comprehensive (it does not include disease classification, dialysis, transplantation); and further specification is required for studies in children. For these and other reasons, we consider the current recommendations for a glossary to be an important starting point, and it will require future expansion and updating.

Achieving consensus among conference attendees, and publication of the conference report and glossary, is only the first step in implementation of a revised nomenclature. The glossary will be freely available on the KDIGO website (https://kdigo.org/conferences/nomenclature/; Table 2). Elements of the glossary will be included in online updates to the newly released (11th) edition of the AMA Manual of Style [13]. Medical journals adopting the recommendations will need to determine how to implement them, and this process will require education of editorial staff as well as proactive communication with au- 
thors, generally and with regard to specific manuscripts. If successful, further implementation in clinical practice, research, and public health will require more widespread dissemination and professional education. Improving communication with patients and the public will require efforts to improve patient education and health literacy for the public, and guides to communication with patients. Professional societies, industry, and patient advocacy organizations will be critical to these efforts.

Advances in research, particularly in precision medicine, will introduce a myriad of new terms and novel concepts requiring incorporation into disease definitions and classifications. In addition, the increasing prominence and participation of patient and caregiver communities in defining research and best practices in clinical care will further elucidate the characteristics of patient-centered terminology. Expanding and updating the KDIGO glossary can be accomplished as part of the activities of future KDIGO guideline workgroups and conferences.

\section{Acknowledgments}

The authors are grateful to Juhi Chaudhari, MPH, at Tufts Medical Center, Boston, MA for assistance with manuscript preparation. The content of this article does not necessarily reflect the views or opinions of the journal organizations represented at the conference. Responsibility for the information and views expressed is limited to the coauthors.

\section{Conflict of Interest Statement}

A.S.L. declared having received research support from AstraZeneca, National Institute of Diabetes and Digestive and Kidney Diseases, and National Kidney Foundation. K.-U.E. declared having received consultancy fees from Akebia, Bayer, and Genzyme; speaker honoraria from Bayer and Vifor; and research support from Amgen, AstraZeneca, Bayer, Fresenius Medical Care, and Genzyme. N.M.D. declared having equity ownership/stock options from Eli Lilly \& Co. M.J. declared having received consultancy fees from Astellas, AstraZeneca, GSK, MSD, and Vifor Fresenius Medical Care Renal Pharma; speaker honoraria from Abbvie, Amgen, Menarini, MSD, and Vifor Fresenius Medical Care Renal Pharma; travel support from Amgen; and research support from Alexion, Amgen, Janssen-Cilag, Otsuka, and Roche. W.C.W. declared having received consultancy fees from Akebia, AMAG, Amgen, AstraZeneca, Bayer, Daiichi-Sankyo, Relypsa, and ZS Pharma; speaker honoraria from FibroGen; and research support from National Institutes of Health. All the other authors declared no competing interests.

\section{Funding Sources}

The conference was sponsored by KDIGO and supported in part by unrestricted educational grants from AstraZeneca, Bayer HealthCare, Boehringer Ingelheim, Fresenius Medical Care, Roche, and Sanofi.

\section{Author Contributions}

Each author fulfills the ICMJE Criteria for Authorship.

\section{References}

1 Levey AS, Weiner DE; editorial team. Staying put, but not standing still. Am J Kidney Dis. 2012 Jan;59(1):1-3

2 Kidney Disease: International Global Outcomes. Consensus Conference on Nomenclature for Kidney Function \& Disease. Available at: https://kdigo.org/conferences/nomenclature/. Accessed April 24, 2020.

3 Plantinga LC, Boulware LE, Coresh J, Stevens LA, Miller ER 3rd, Saran R, et al. Patient awareness of chronic kidney disease: trends and predictors. Arch Intern Med. 2008 Nov; 168(20):2268-75.

4 James SL, Abate D, Abate KH, Abay SM, Abbafati C, Abbasi N, et al.; GBD 2017 Disease and Injury Incidence and Prevalence Collaborators. Global, regional, and national incidence, prevalence, and years lived with disability for 354 diseases and injuries for 195 countries and territories, 1990-2017: a systematic analysis for the Global Burden of Disease Study 2017. Lancet. 2018 Nov;392(10159):1789-858.
5 Bikbov B, Purcell CA, Levey AS, Smith M, Abdoli A, Abebe M, et al.; GBD Chronic Kidney Disease Collaboration. Global, regional, and national burden of chronic kidney disease, 1990-2017: a systematic analysis for the Global Burden of Disease Study 2017. Lancet. 2020 Feb;395(10225):709-33.

6 Saran R, Robinson B, Abbott KC, Agodoa LY, Bhave N, Bragg-Gresham J, et al. US Renal Data System 2017 annual data report: epidemiology of kidney disease in the United States. Am J Kidney Dis. 2018 Mar;71(3 Suppl 1):S1-S676.

7 Hsu CY, Chertow GM. Chronic renal confusion: insufficiency, failure, dysfunction, or disease. Am J Kidney Dis. 2000 Aug;36(2): 415-8.

8 Levey AS, Eckardt K-U, Dorman NM, et al. Nomenclature for kidney function and disease: report of a Kidney Disease: Improving Global Outcomes (KDIGO) Consensus Conference. Kidney Int. 2020 Jun;97(6):1117-1129.
9 Committee on the Quality of Healthcare in the United States. Institute of Medicine. Crossing the Quality Chasm: A New Health System for the 21st Century. Washington (DC): National Academy Press; 2001.

10 Oxford Dictionary of English. 3rd ed. Oxford, UK: Oxford University Press; 2010.

11 Kidney Precision Medicine Project. Available at: https://kpmp.org/

12 Tong A, Levey AS, Eckardt K-U, et al. Patient and caregiver perspectives on terms used to describe kidney health [e-pub ahead of print]. Clin J Am Soc Nephrol. https://doi.org/ https://doi.org/10.2215/CJN.00900120.

13 Christiansen S, Iverson C, Flanagin A, et al. American Medical Association (AMA) Manual of Style: A Guide for Authors and Editors. 11th ed. Oxford, UK: Oxford University Press; 2020 . 